\title{
The Good, the Bad and the Ugly: A Retrospective on Telos
}

\author{
Scott G. McNall
}

An Internet search for Telos, turns up the defense contractor, Telos. There is some irony in this. Paul Piccone, in response to an interviewer's question in 1999 about the impact of Telos, noted that the magazine "thrives outside a mainstream which mostly does not understand it, does not appreciate it, and. . does not take it seriously" (fall, 1999:140). He added that "Telos remains the project of a few intellectuals and of limited readership still interested in the Truth, and optimistic, that, despite the general cultural decline, there are still a lot of possibilities for a society," however mesmerized it is by material success, and unable to recognize its spiritual impoverishment. There is the possibility that Paul was wrong about his bleak assessment of the reach and influence of the journal.

It is impossible to write about Telos without writing about Paul Piccone, because he was the founder, leader, and energy behind the magazine, outlasting editorial board changes, theoretical infighting, and changing world historical circumstances. He brought together in symposia, conferences, and other settings a group of scholars deeply committed to their own positions, who were not shy about entering into loud, long and sometimes tendentious arguments in support of their interpretation of some obscure theorist or theory. The first Telos event I attended was at Washington University, where Paul was still employed. The conference focused on the irrationality of a rational society. At one point, Alvin Goulder, a dominant force in the sociology department and sociology, began to shout from his seat, "Scandal! Scandal!" drowning out the speaker. I don't believe anybody ever understood what the scandal was, but I learned that being around the Telos group was not going to be boring. Paul seemed to view his job as provoking discussion and not infrequently "setting people right." He was exceptionally well read and knew the work of the founding fathers of the discipline well. His range of interests was broad, and the topics he tackled on behalf of the journal were vast. He and the editorial board grappled with such topics and issues as Stalin, Marx, Lenin, Luxemborg, Bernstein, popular culture, music, Weber, Carl Schmitt, democracy, law, Russia, Perestroika, Adorno, Heidegger, Castoriades, Habermas, theology, populism, federalism, paleoconservatism, ecology, South Africa, organic intellectuals, communitarism, the New French Right, and Horkheimer. It might seem these topics aren't connected but there are strong unifying threads, as we will see. So what Telos was all about?

Telos was founded in 1968 with the purpose of consistently attacking the "forces of instrumentalization, homogenization, commodification, one-dimensionality, and identity logic" (Gross 1992-1993:7). This consistency of purpose led to what some would regard as unusual or unique political and theoretical positions, which I'll explain below. The journal was seen, to use Paul's language, as an antidote to a provincial student culture "cretinized by decades of the intellectual cold war" (Piccone 1999:133). To accomplish this task it introduced American students and professors to Continental scholars who had been struggling with the political and economic wreckage of World War II, and who were searching for theoretical explanations of what had gone so wrong. Nothing in Marx or Engels prepared intellectuals for Stalin or the Nazis, nor the broad social reaction against them. When Telos was founded very little of the theoretical work of the Frankfurt School was available in English and most Westerners only knew about Marx's Economic and Philosophic Manuscripts, because they had read Marcuse's One Dimensional Man. Telos was a place to turn to try to understand the Vietnam War, the rise of crass commercialism, the inability of a left-leaning intellectual class to have any seeming impact on the larger political and economic landscape, the growing power of transnational corporations, and laws that gave tax breaks to the wealthy and eroded the freedom of 
working men and women.

If one were to pick up any single issue of Telos there would be several possible reactions. You might feel that you had just joined a conversation of old but grumpy friends who had been chewing over one issue for decades. Or you might feel outrage, given a particular position or argument offered. Others might feel as though they were overcome by ether, as some of the prose was simply awful-long Baroque sentences embedded in long paragraphs that never seemed to have any point or any connection to the empirical world. The more time and energy one commits to trying to understand such work, the more likely one is to believe they are part of an important in-group with an important message that can only be deciphered by the elect. Whether or not the Telos enterprise was valuable can only be decided by trying to understand the evolution of the journal and the reasons it blazed a particular path.[2]

\section{| The Frankfurt School and Critical Theory}

Some have seen Telos as a direct descendant, or offshoot, of what is know as the Frankfurt School. However, the problems that the founders of that school were addressing, and the historical circumstances, differed greatly from those of Telos. You could not have been alive in the 1960s and early 1970s without thinking that there was something wrong with Western culture but what, and how to develop a position from which to develop alternatives were not exactly clear. Adorno and Horkheimer, having fled to the United States from Nazi Germany, established The Institute for Social Research in New York. The first work of Adorno's that was widely available was The Authoritarian Personality, which "explained" the Holocaust as a psychological aberration. The United States and other Western liberal democracies were the standard against which Nazi Germany and fascist Italy should be compared. Of course, this tended to legitimate liberal ideology as "normal." The problem with this reasoning is that much earlier Horkheimer and Adorno had published the Dialectic of the Enlightenment in which it was argued that liberalism was simply another expression of modernization or the Enlightenment, which also lead to Stalinism, the New Deal, and Nazism. This makes sense if you see the triumph of Weberian rationalism in the American state, as well as all other modern states. As such, it leaves no place, literally, for self expression, no space in which to craft new political or economic systems. Marcuse, who drew heavily from the Dialectic of the Enlightenment, understood two very important things. First, he understood that the old, tired Marxism of the Soviet establishment had no room in its theoretical toolkit for the concept of alienation. Alienation was supposed to disappear when the economy was transformed. Marcuse did a brilliant job of rescuing that part of the Marxist project that understood alienation as a product of modernization and not any particular economic system. Like Adorno and Horkheimer, he saw alienation as product of the Enlightenment. Second, he understood that mass culture was degraded in capitalist societies to a marketing device. These insights, which form part of the basis of Critical Theory, brought the Telos project close to Critical Theory and the Frankfurt School. Critical Theory, as understood and explicated by the Telos editors and writers, celebrated social difference, particularity, and inclusiveness. There was an abiding concern with finding and/ or developing sources and counterweights to the development of a rational society that dominated all aspects of social and economic life. Early issues of the journal read almost like a plea to understand the real nature of liberalism, its Enlightenment roots, and what would happen if liberalism was left unchallenged.

However, Telos, and Piccone in particular, inveighed against the uncritical acceptance of Critical Theory and the Frankfurt School by the American Left and the New Marxists. Most obviously, they opposed all of the old Marxist economic dogmas and they cautioned against appropriating whole cloth theories and ideas that had been developed in Europe in the 1930s. They rejected the psychoanalytic turn taken by some Marxists. They eventually challenged Marcuse because they saw his later work being used to legitimate the view of the New Marxists and the New Left that all social problems were basically due to "pre-modern residues whose systematic elimination" was seen as the key to development of a progressive agenda (Piccone 1999:135). They offered, instead, the early Marcuse whose work in the 1920s pointed to the "recovery of a Being lost and forgotten because of the generalization of commodity fetishism" (Piccone 199:137). There were others, of course, who also took up the challenge of locating the real Human Being crushed by the grinding wheels of modern societies. Note, the distinction: the reference is to modernism itself, not captalism. The journal introduced the work of Continental theorists and scrutinized them closely. Heidegger was examined and found wanting because of the hollowness of his concept of Being. Other phenomenologists were tossed in the rubbish bin of history, where they properly belong.

All theorists are ultimately challenged to explain why their perspective is more plausible than somebody else's. 
In the case of social theory, we sometimes rely on comparisons. For example, if it is believed that Nazi Germany grounded their concepts of Aryan supremacy in pre-modern notions of the tribe, then it follows that tribal behavior must be anathema to the develop of a just and modern society. If we believe that human beings can reach their full potential only when free to express their rational economic interests (assuming they know what they are), then it follows that any society that limits economic choices must be "unfree" and that people can't realize their full potential. Sometimes people flat out admit that they are Kantians and claim there are certain a prioris that define any just society. It's just wrong to kill your neighbor, steal her cow, and appropriate his property.

New Critical Theory sought to overcome this problem of grounding through the combination of science and Social Pragmatism, primarily the work of Dewey. A pragmatist is faced with the problem of how to skin a cat and studies the various means and methods of doing so, chooses the most efficient ones, and does it. (Or does not do it, because whether or not we even skin cats is culturally determined and culture must have its due.) Science is a powerful tool. It does away with tradition, superstition, and transcends culture. It also leads, as Marcuse and others have noted, to technological overdetermination. That is why Telos challenged this variant of Critical Theory, because it feeds the notion that tradition is a barrier to social progress and fails to understand that social progress itself, a product of Enlightenment thinking, is ultimately soul destroying.

Another variation of Critical Theory held up for scorn was the work of Habermas, a product of the Frankfurt School. As a product of post-war Germany, Habermas set out to determine how human beings could create vibrant, democratic societies. Picking and choosing his theories carefully he grounded his work in a variant of linguistic theory that suggests we are all "competent communicators." We are hard wired to reason rationally. If we sit around and talk about it long enough, we can agree on the basic principles of a just society and manage ourselves as though we are a New England Town Hall, or a graduate seminar. Though I personally find these ideas silly, I admire the single-minded effort to theorize some way that a society could work better than others.

As Piccone (1990:138) saw it, and several others, Critical Theory, whether the version inspired by Dewey or Habermas, had taken a wrong turn. They had rejected everything of value in the work of the founding fathers of Marxism and Critical Theory, viz., the theory of alienation, the great refusal, negativity, etc. In its place was a vacuous acceptance of American social science and English analytic philosophy. This shift away from Critical Theory and the work of Habermas caused several members of the editorial board to depart. The reasons are important to understand.

\section{Populism and Federalism}

Telos took up the banner of populism and federalism as one of their versions of the Great Refusal. This was perfectly compatible with the goal of finding alternatives to the iron cage of modern governments. It is not stretching things to suggest that the Telos writers saw the modern state as a protection racket, managed by a New Class that carried out its functions and legitimated its existence. They argued that people failed to realize how they had given up individuality and freedom. The solutions offered were populism and federalism. This was confusing to some who read the journal, because many understand populist movements to be retrograde, giving rise to right-wing demagogues and other folk of the fringe.

To understand what Telos writers and Piccone meant by federalism it is useful to consider our own Constitution. As many scholars have noted, it is replete with contradictions and built-in tensions between the federal government and the rights of the states. The classic debates and struggles between John Adams and Thomas Jefferson illustrate this. To use the language of Telos, Jefferson was arguing for particularity, individuality, autonomy and freedom from a central government. He wanted to preserve what was unique about Virginia and allow other states to do follow their own paths to development. Deeply influenced by the French Revolution, he saw the need to hold conventions and modify the Constitution based on the needs of the citizens. He was, in short, a populist. Adams, on the other hand as a federalist, saw the necessity for a national army, sided with Hamilton in terms of creating a federal banking system, and saw the need for interstate commerce to be regulated by the federal government. Our current Federal Government holds these powers and, unfortunately, many more.

The Telos form of federalism would have us go back to the founding of this country, when there was a minimalist federal government based on a lose coalition of willing states, each with its own distinct cultures and interests. They made no assumptions that there was a universal Truth to guide all action, or one form of civil 
government superior to all others. They embraced democracy without adding the baggage of religion. They sought real communities of autonomous individuals as models to celebrate and understand.

This lead to the embrace of some strange causes as well as bedfellows, and to some arguments within the Telos camp. As Paul's urging, California State University, Chico decided to host one of the Telos mini-conferences. Our keynote speaker, who was from the South, seemed to have come to us from another historical period-the Reconstruction. He was an unalloyed apologist for all things Southern and exemplified what Cash called, "The Mind of the South." He was a great hit with the few monarchists in the history department and some of the all-purpose conservatives on the faculty. When I pressed Paul on his reasons for inviting this gentleman and entertaining his ideas, he explained we needed to celebrate alternative ideas and modes of consciousness. It was also explained that he was a communitarian, which brings me to another set of issues.

\section{| The Left Versus the Right}

Telos saw it as its job to educate an ill-informed Left. I've noted at the beginning of this essay that Telos wanted to set the record straight about what the members of the Frankfurt School had really said and thought, and to rescue that part of the Marxian project that understood social alienation to be as important as the divisive economy, if not more so. Neo-liberals (to distinguish them historically) were seen as enemies of clear thinking. According to Piccone (1999:141), neoliberals celebrated bourgeois values as universal truths. They were "committed to ever growing state intervention, bureaucratic rationality, . . formal equality, social justice, representative liberal-democracy, and unrestricted inclusiveness." This represented the ideology of a New Class that reduced politics to procedure and marginalized its opponents as criminals or as people in need of therapy. Neoconservatives, centralizers like the neoliberals, were painted with the same brush. The point was that old labels of Left and Right were no longer meaningful and actually obscured important facts about both modern liberals and conservatives.

Telos operated in an international context and with a broader historical perspective than other organs of the left. Telos writers understood that often governments will strengthen their ability to curb all dissidence by acting in the name of the people, absorbing all forms of opposition. The Jacobins claimed to be acting for the repressed, the Third Estate, and they shaped an undifferentiated mass called "citizens." Lenin and Stalin acting in the name of the people strengthened a central government and stamped out all loci of freedom and opposition. The bureaucratic New Deal and Welfare state, some suggested, managed to do the same. Sources of opposition celebrated by the left, e.g., the civil rights movement, the student movement, were described by some as forms of "artificial negativity." They were artificial because they were, in fact, part of the state apparatus. As noted by the Telos writers, the civil rights movement was subsidized in part by a liberal state and embraced by the state in order to give the bureaucracy time to accommodate and make the changes necessary to continue to function. (I don't agree with this analysis in part because I don't believe the New Classes, or the modern bureaucratic state, operates as rationally as described.) States, unable to be this nimble, end up collapsing under their own weight; that is, the bureaucratic apparatus does not create the conditions necessary for its own reproduction. A state, then, must absorb "otherness" to survive. Telos predicted the devolution of the Soviet Union based on its understanding of a bureaucratic apparatus that brutally stamped out all opposition. The velvet glove of modern democracies was seen as particularly insidious.

What might be effective was to strengthen autonomous groups. The terms used to described such self-actuating and self-governing bodies was communitarianism. The concept is more useful than it might seem at first glance, especially when coupled with a celebration of populism and federalism. There have been several mass demonstrations against the World Trade Organization (WTO), as well as the North American Free Trade Agreement (NAFTA). If you characterize the groups that show up to demonstrate in terms of left, right, conservative, or liberal, you have a hard time understanding people's motivations, because you will find members of conservative religious groups protesting right beside members of labor groups, farmers' cooperatives, environmental activists, etc. These disparate groups are, however, joined on the topic of individual freedom and autonomy, and often a desire to strengthen local and regional economies and cultures. Such groups would be seen as sources of real negativity, locking arms in the Great Refusal.

The work of Carl Schmitt, who is probably unknown to many theorists outside the Telos circle, was offered as a means of understanding how and why autonomous groups form. Schmitt was a Nazi, who wrote during the late 1920s to the early 1940s. The very fact that Telos reviewed and discussed his work was enough for some to brand 
the project as "conservative" and deeply suspect. Schmitt predicted the decline of federations and nation states, seeing them as inherently unstable, while Telos celebrated loose federations. For the communitarians and Telos federalists it was Schmitt's understanding of homogeneity that was intriguing. A homogeneous group had similar mental constructs, life experiences, religious and political values, separate from the state and therefore homogeneity could be a real and meaningful source of authentic negativity. (Of course, if you read Schmitt's work as a celebration of the "volk" and Aryan values, you would see this as an apology for and potential justification of the Nazi regime.) While it was useful to introduce Schmitt to American readers, there were mainline sociologists whose work on culture and subculture was more succinct and potentially less inflammatory.

\section{Multiculturalism and All That}

The gist of the above is that there is a remarkable consistency of analysis in the Telos pieces. If you were not familiar with the journal you might be startled to find that multiculturalism (which included all identity programs, "survivor" groups, women's studies, queer studies, and so on) was not regarded as a good thing. The reasons are intriguing. If a liberal society like ours passes laws, which it does, declaring that all difference is to be ignored, then it leads to a crypto-status and, ultimately, to the criminalization of difference. It leads necessarily to political correctness: to approved speech, and speech that is not approved. Colleges have generally given up on trying to create "speech codes" but many tried usually to the point of absurdity. It is good to understand things from many perspectives. It's good to see that-from the perspective of Critical Theory- we are well down the path described in dystopian fiction.

\section{The Good the Bad and the Ugly}

Telos, the journal, the editors and others who came together for meetings, conferences, helped an immeasurable number of people: those of us who were learning for the first time about Critical Theory and the Frankfurt School; those of us who thought Marx might have the answer to some of the political and economic problems facing the country; those of us who had not been exposed to Continental Social Theory, as well as some more arcane members of the theoretical establishment; those of us trained by graduate departments that only taught the sociological "giants," (e.g., Durkheim, Weber, Mead, and Cooley); and, finally, those of us who might have been lazy thinkers and believed that the answers to Vietnam, the commodification of all culture, and the vacuity of modern society were easy to find. Some of us passed this legacy on to our graduate students; some used the ideas to sharpen our own thinking and to look beyond the borders of this continent for political movements and parties from which we could learn strategy, tactics, and wonder what could pose legitimate and workable challenges to our own government.

In preparation for writing this essay, I considered more closely the whole run of Telos than I ever had before. There were issues raised in these journals to which I will return, even though many of the articles I found relevant are over a decade old. That says something about the staying power of the core set of beliefs that undergirded the journal. I don't think I realized until now how important Hegel was to the whole effort. By this I don't mean a search for some ultimate truth, or the belief that history has an inevitable end, regardless of the title of the journal. I mean, quite simply, the understanding that the main problem facing humans in modern societies is alienation. We can talk, although I don't think productively, about alternatives to capitalism but the real problem is modernism-and its lovechild, post-modernism - and how they have absorbed all sources of potential change, all negativity.

The journal literally sought high and low for challenges to modernism, in obscure third parties in Europe, Asia, and within movements in the United States. They considered the virtues of regionalism in the United States, wondered if some of what the South hoped for in the pre-Civil War period wasn't valid, and considered the virtues (even though bizarre) of the French Right, and the Central European Union.

They were unrelenting in their criticism of liberal democracies, which lead to no end of grief. But they understood, as few did and still do, that the trends observed by Adorno and Horkheimer that lead the rise of fascism and Bolshevism were present in our own modern society. They challenged members of the New Left who tried to appropriate theories grounded in other historical realities; and excoriated those who saw pre-modern and traditional systems and ideals as something to be uprooted to spur progress. The New Left was also-appropriately-chastised for defaulting to the liberalism of the Democratic Party.

They were remarkably consistent, theoretically. If you understand alienation to be the central problem, then it follows that you must search for and create alternatives that often exist only in the interstices of modern capitalist 
society. This was not a celebration of the atavistic; it was a search for real alternatives, real ways to create decent and humane societies.

There were many problems and issues that Telos did not tackle. They never looked at problems of population growth, or resource depletion. They could not have anticipated that Russia would re-emerge as a powerful political force, having overcome the vestiges of bureaucratic necrosis that plagued the Soviet Union, and garnered new wealth as the price of oil sky rocketed. They did not anticipate the re-emergence of nationalist movements across the globe, although they might see these movements as possible sources of opposition to the homogenizing forces of the WTO or the World Bank. There was little or no understanding of ethnic violence, or cleansing (although there were discussions about whether NATO's intervention into Serbia made sense), or Islamic fundamentalism. There were and are many sources of alienation, decadence, and degradation.

If I have any complaints about Telos, it has primarily to do with the fact that I did not think that on the whole they were very good sociologists. (Of course, some of the writers weren't sociologists.) Sociology is a science, at least in theory. This means that we look for patterns in behavior; try to develop theories based on our observation of what real people do when they are in groups, and systematically try to disprove our ideas. Like "real" scientists, we look for the negative cases. There are problems, of course in developing rigorous theory, because we seldom get to experiment on real people, and there are few opportunities to engage in systematic and rigorous testing of our ideas. Normally, we compare groups across periods of time, in different situations (countries) and try to build explanations in that manner. This minimalist characterization does not describe most of what was in Telos. (And, it wasn't because such submissions were actively discouraged; they just weren't part of the ethos.)

The real problem for me is that if I tried to craft a social movement, program, set of ideas that would animate people, I could not find it in Telos. When people say to "think globally, act locally," I take this to mean that on a practical basis we ought to be able to do something simple like win a local election, elect people to office who support what we value. Telos was on to something when its writers understood that political and economic ideas needed to resonate with people and that trying to craft solutions that were Federal (as we mean that term today) were doomed. My charge of political irrelevance could, of course, be laid at the door of almost every professional journal and association. We focus on theory at the expense of what is in front of our noses and we often substitute theorizing for the framing of solutions that might make a difference. We search for answers in the texts of Marx, Weber, and Durkheim. Hermeneutics is a stand-in for observation and the development of answers to the problem of alienation.

My own concerns at the moment relate to the degradation of the environment, the loss of biodiversity, global warming, and the possibility that humans can destroy the conditions which make our existence possible. We've made great progress so far! When I pick up an article, or am asked to review a piece, explaining for example that Marx had an environmental ethic, my response is "So what!" Whether he did (it's stretching it to suggest he did) or did not is simply beside the point. The point is to figure out how we can get people to listen and take responsibility for what they are doing. It's a huge and daunting challenge. We know that modernism is responsible for most of our modern pathologies, inequalities, and destruction of the very means of survival. So, what are we going to do about it?

\section{Endnotes}

1. Scott G. McNall is currently the Executive Director of the Institute for Sustainable Development at California State, University Chico.Smcnall@csuchico.edu
2. The discussion of the journal's evolution draws heavily on the interview with Paul Piccone published in Telos (fall 1999:133-166).

\section{References}

Gross, David. 1993-1994. "Rethinking Traditions." Telos. Winter:5-10.

Piccone, Paul. 1999. “Interview.” Telos. Fall:133-166. 